\title{
Reasons for low modern contraceptive use-Insights from Pakistan and neighboring countries
}

Batool Zaidi

Sabahat Hussain

Follow this and additional works at: https://knowledgecommons.popcouncil.org/departments_sbsr-rh

Part of the Demography, Population, and Ecology Commons, Family, Life Course, and Society Commons, International Public Health Commons, and the Women's Health Commons How does access to this work benefit you? Let us know!

\section{Recommended Citation}

Zaidi, Batool and Sabahat Hussain. 2015. "Reasons for low modern contraceptive use-Insights from Pakistan and neighboring countries," Literature review. Islamabad: Population Council. 


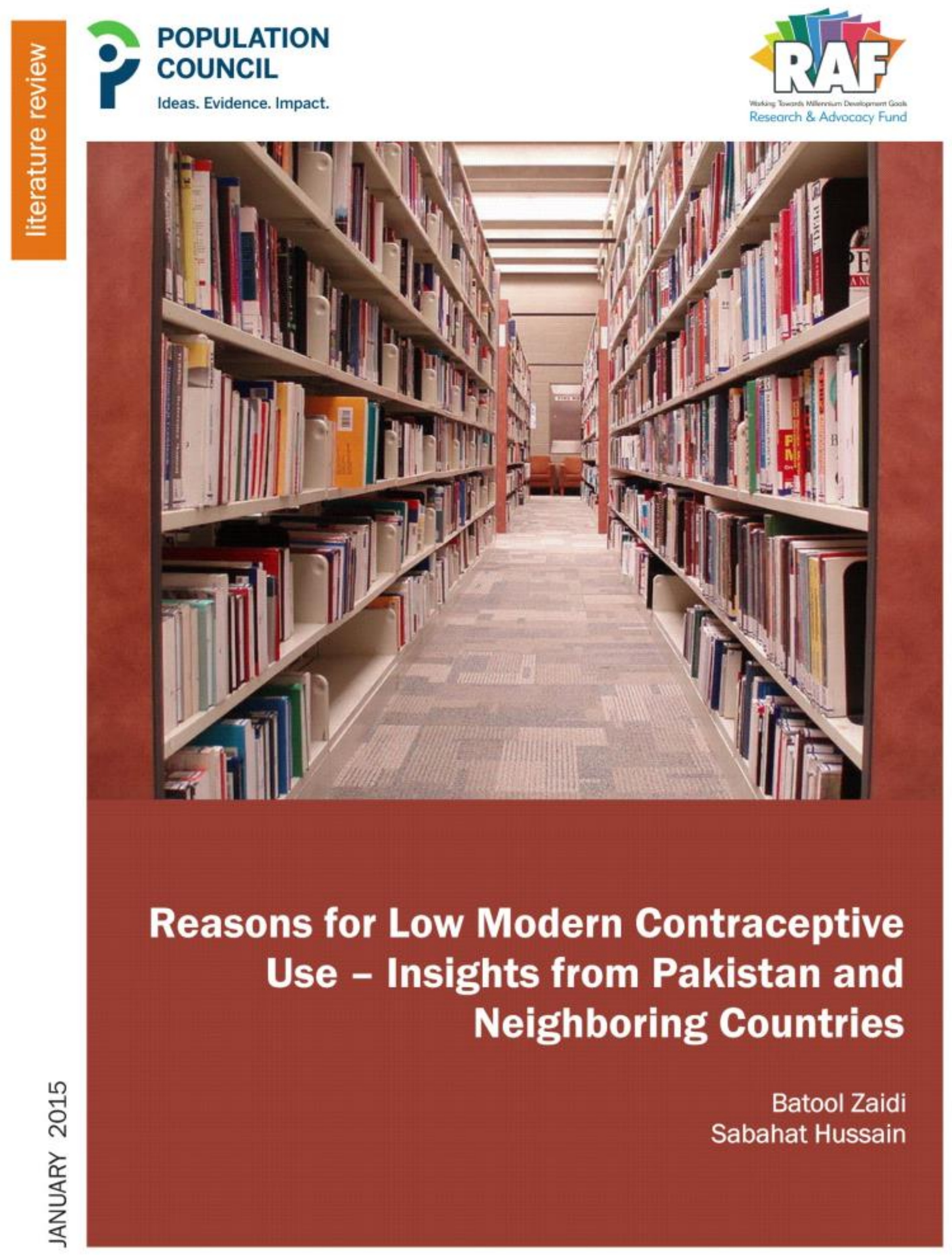





\section{POPULATION}

The Population Council confronts critical health and development issues-from stopping the spread of HIV to improving reproductive health and ensuring that young people lead full and productive lives. Through biomedical, social science, and public health research in 50 countries, we work with our partners to deliver solutions that lead to more effective policies, programs, and technologies that improve lives around the world. Established in 1952 and headquartered in New York, the Council is a nongovernmental, nonprofit organization governed by an international board of trustees.

Population Council

House \#7, Street 62, F-6/3, Islamabad, Pakistan

Tel: 92518445566

Fax: 92512821401

Email: info.pakistan@popcouncil.org

Web: http://www.popcouncil.org 


\section{POPULATION
COUNCIL \\ Ideas. Evidence. Impact.}

The Population Council confronts critical health and development issues - from stopping the spread of HIV to improving reproductive health and ensuring that young people lead full and productive lives. Through biomedical, social science, and public health research in 50 countries, we work with our partners to deliver solutions that lead to more effective policies, programmes, and technologies that improve lives.

(C) 2015 The Population Council, Inc.

\section{Declaration}

"I have read the report, Reasons for Low Modern Contraceptive Use - Insights from Pakistan and neighboring countries and acknowledge and agree with the information, data and findings contained."

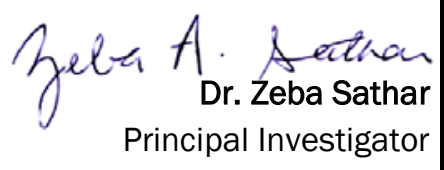

\section{Acknowledgment}

Investigating the Low Patterns of Modern Contraceptive Use in Pakistan is a project funded by the Maternal and Newborn Health Programme, Research and Advocacy Fund (RAF), and is implemented by Population Council, Pakistan.

\section{Disclaimer}

This document is an output from a project funded by the UK Department for International Development (DFID) and the Australian Department of Foreign Affairs and Trade (DFAT) for the benefit of developing countries. The views expressed and information contained are not necessarily those of or endorsed by DFID, DFAT, or the Maternal and Newborn Health Programme, Research and Advocacy Fund (RAF), which can accept no responsibility or liability for such views, for completeness or accuracy of the information, or any reliance placed on them. 


\section{Reasons for Low Modern Contraceptive Use - Insights from Pakistan and Neighboring countries}

\section{Summary}

This report forms part of an extensive research project to determine why, despite evident demand, contraceptive prevalence remains so low in Pakistan, especially for modern methods. The research has been conducted by the Population Council with the support of the Research and Advocacy Fund (RAF) and comprises four component studies, including: (1)a review of relevant academic, program and policy literature; (2) a qualitative study of perspectives of men, women and service providers in the country on family planning; (3) a situation analysis of contraceptive quality, supply and access factors at health facilities; and (4) an examination of supply chain issues affecting the availability of contraceptives.

This report presents the first study, i.e., the review of academic, program and policy literature on contraceptive demand and supply in Pakistan, and neighboring regions where relevant. The purpose of this review is two-fold:

Firstly, to inform and influence the study design for the following three components by identifying the questions that remain unanswered and require further in-depth probing, particularly as they relate to issues of sociocultural costs and actual costs of using modern contraception. Secondly, to function as a resource for those interested in pursuing research and program development in family planning in Pakistan. In order to meet the second purpose, this review utilizes PDHS 2012 data regarding the reasons for non-use, source of supply of contraceptives, and access-related issues to update many of the associations found in the literature. It also compares these to prior analyses from the PDHS 2006-07 and Family Advancement for Life and Health (FALAH) endline to assess whether there have been any significant changes over the last five-year period.
In addition, this review includes an assessment of current policies and strategies adopted by both the public and private sectors to improve the uptake and quality of FP services in general, and uptake of modern contraceptives in particular. It builds on major studies of shortcomings in the public delivery of family planning services (Ahmed 2013; Mir and Rashida 2013; Sathar and Zaidi 2010). It also draws on evaluations of earlier interventions and operations research, including lessons from successful interventions by the Population Council, Marie Stopes International, Greenstar Social Marketing, and other Government of Pakistan's (GOP) initiatives, as well as neighboring countries that have worked in more effective utilization of family planning services.

The review finds that supply-side factors (including poor access to FP services, lack of counseling and technical knowledge of unmotivated providers, and insufficient of availability of affordable modern methods) are the major obstacles to the uptake of modern contraceptives, rather than the more frequently cited demand-side factors (including husband disapproval and religious opposition). The high rates of contraceptive discontinuation, widespread fear of side effects, and sharp wealth differentials in contraceptive use all point to inadequate supply of a wide array of FP services that are affordable and accessible to all groups. While the high prevalence of couple-methods, increasing demand for contraception by men and the high rates of induced abortions indicate that the husband or religious opposition are not the main culprits of low contraceptive uptake. The second component of the study therefore seeks insight from indepth interviews with men and service providers, along with women. While the third and fourth components of the study unpack issues around the quality and availability of a variety of modern contraceptive methods. 


\section{Introduction}

Pakistan has one of the highest fertility rates in Asia, and the lowest rates of contraceptive use, resulting in poor reproductive health indicators for women and high neonatal mortality (Aga Khan University 2012). In 2002, the country's abortion rate was estimated at 27 per 1,000 , while the rate of post-abortion complicationsresulting largely from induced abortions-stood at 9 per 1,000 ; by 2012, the abortion rate almost doubled to 50 per 1,000 and the rate of post-abortion complications rose to 15 per 1,000 (Sathar et. al 2014).

Despite this evident and increasing desire to limit pregnancies, substantial growth in the contraceptive prevalence rate (CPR) has been lacking. Of greater concern, compared to five years ago, an increasing proportion of women are unsure about whether they will use contraception in the future. Moreover, exposure to family planning messages through media has diminished over the same period. In 2006-07, close to half of married women of reproductive age in Pakistan had come across a family planning message on the TV, radio or newspaper. By 2012-13 this proportion had halved to only 1 in every 4 women. Even amongst the small proportion who had been exposed to these messages, less than 30 percent were exposed to messages about using contraception, the others only read, heard or saw messages about the advantages of a smaller family.

The first section of this report presents a detailed picture of the state of contraceptive use in Pakistan. It focuses on addressing the following questions:

- How many women are trying and currently using contraception?

- Who are these women? What methods do women use? How often do they discontinue using methods?

- How many women have a need for family planning? Why are most of these women not using contraception?
The second section of the report explores the possible reasons behind low contraceptive uptake from the perspective of users (both women and men). In order to do so, it unpacks the following statements that are often found in literature on contraceptive prevalence in Pakistan:

- Knowledge of contraceptives is universal;

- The low status of women, most commonly measured through mobility and decision-making, is the underlying factor behind low contraceptive use;

- Social costs, primarily in the shape of husband's disapproval and religious opposition, are a major obstacle to contraceptive uptake;

The third section of this review also focuses on the obstacles to contraceptive uptake, but from the service provision perspective. It addresses the following questions:

- Are lack of access and monetary costs of contraception significant obstacles to contraceptive use?

- Where are contraceptive methods available? Which methods are provided?

- Why are fear of side effects and health concerns around contraceptive methods significant contributors to low uptake and high discontinuation?

- What role do the service providers' knowledge and skills (both technical and interpersonal/counseling) play in low contraceptive uptake?

- Why has the public sector failed to implement a successful family planning program?

- What is the contribution of the private sector? 


\section{Section 1: Status of contraceptive use in Pakistan}

At the onset of the fertility transition in the early 1990s, Pakistan's Contraceptive Prevalence Rate (CPR) showed a promising, albeit late, growth of 1.6 percent per annum after remaining extremely low from the 1950 s to 1980 s. Current use more than doubled from 11 percent in 199091 to 28 percent in just a decade. However, this growth spurt was short-lived. The first decade of the new millennium saw the increase in CPR fall to 0.7 percent per year on average. The Pakistan Demographic and Health Survey (PDHS) 2006-07 found that the CPR had actually fallen and contraceptive use had stagnated between surveys. Figures from the latest PDHS indicate only a modest increase in the CPR from 30 percent in 2006-07 to 35 percent in 2012-13. The increase in CPR over these two decades has been due to increases in the uptake of both modern and traditional methods. Both types of methods saw a threefold increase over this time period, with current use of traditional methods increasing from 3 percent to 9 percent and modern method use from 9 to 26 percent. (Figure 1) In 1990-91 a quarter of current users were using a traditional method and by 2012-13 this proportion was the same, the only change was that the rhythm method gave way to withdrawal.

Figure 1: Trends in current use of contraception

- Modern $\quad$ Traditional

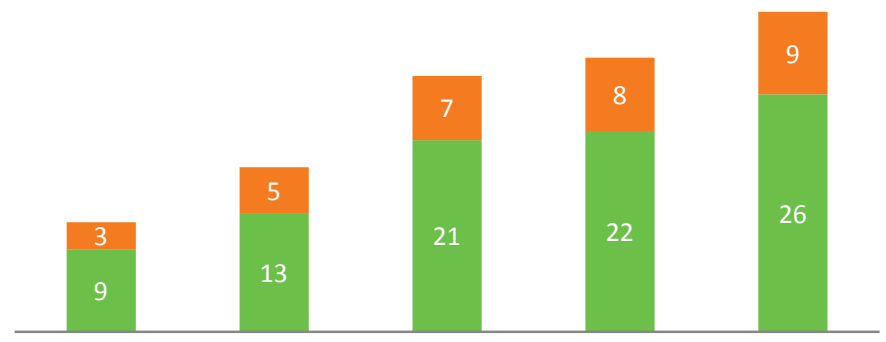

PDHS 1990-91 PCPS 1994-95 PRHFPS 2000-01 PDHS 2006-07 PDHS 2012-13

Sources: Demographic and Health Surveys (1990-91, 2006-07 and 2012-13), Pakistan Contraceptive Prevalence Survey (1994-95) and Pakistan Reproductive Health and Family Planning Survey (2000-2001)

Despite increases in prevalence rates, Pakistan continues to have one of the lowest contraceptive prevalence rates in the region, second only to Afghanistan. India, Bangladesh, and even Nepal now have contraceptive prevalence rates of at least 50 percent. Moreover, while the proportion of traditional methods users in Pakistan is similar to those in its neighboring countries ( 7 to 9 percent), the prevalence of modern contraceptive use remains much lower (26 percent compared to a range of 43 to 53 percent). (Table 1)

Table 1: Contraceptive prevalence rate by country and type of method

\begin{tabular}{llccc}
\hline Country & Year & $\begin{array}{c}\text { Any } \\
\text { method }\end{array}$ & $\begin{array}{c}\text { Modern } \\
\text { methods }\end{array}$ & $\begin{array}{c}\text { Traditional } \\
\text { methods }\end{array}$ \\
\hline Bangladesh & 2011 & 61 & 52 & 9 \\
India & $2005-06$ & 57 & 49 & 8 \\
Nepal & 2011 & 50 & 43 & 7 \\
Pakistan & $2012-13$ & 35 & 26 & 9 \\
\hline
\end{tabular}

Source: Demographic and Health Surveys

Family planning services are still primarily used to limit childbearing with three-quarters of current users are practicing contraception for the purpose of limiting. This is also reflected in age-specific CPRs, which are higher for women aged 35-39, and parity-specific rates, highest for women with 3 or more children.

Does the prevalence of contraceptive use differ by regional context?

The regional variation in development levels within Pakistan is reflected in contraceptive use differentials as well. Since the beginning of the fertility transition, unsurprisingly, Punjab has had the highest CPR and Balochistan the lowest. By 2012-13, the CPR in Punjab was double that of Balochistan, 41 percent versus 20 percent. Sindh and KP fall in the middle of this range, with CPRs of 30 and 28 percent, respectively. Bifurcating the provincial differentials further by rural urban residence highlights greater disparities in the prevalence of family planning. In all provinces, women in urban areas have higher contraceptive use rates than those residing in rural areas. However, rural Punjab's CPR is actually higher than Balochistan's urban figure, indicating the dire situation in Balochistan. Urban-rural differences in Sindh are the starkest; the CPR in rural Sindh is even lower than that of rural Balochistan. This suggests that the overall CPR of Sindh is comparable to that of KP primarily because of the contribution of Karachi's high CPR. These differentials indicate that national-level statistics are insufficient to understand or address low contraceptive prevalence. 
What methods are Pakistani couples using?

Up until 2006-07, female sterilization was the most common choice of contraceptive method amongst Pakistani women. This was followed by condoms and withdrawal. Over the next five years, much of the increase in CPR was due to an increase in the uptake of withdrawal and to a lesser degree, condoms. As a consequence, an equal proportion of Pakistani women now currently use these three methods (method-specific CPR ranges from 8.5 to 8.8 percent each). Other modern methods including pills, IUCDs and injectables comprise the remaining portion of the contraceptive method mix. These methods have seen marginal increases in uptake, with the pill actually showing a slight decrease in the last five years. (Figure 2)

Figure 2: Trends in current use of contraception by method and survey year

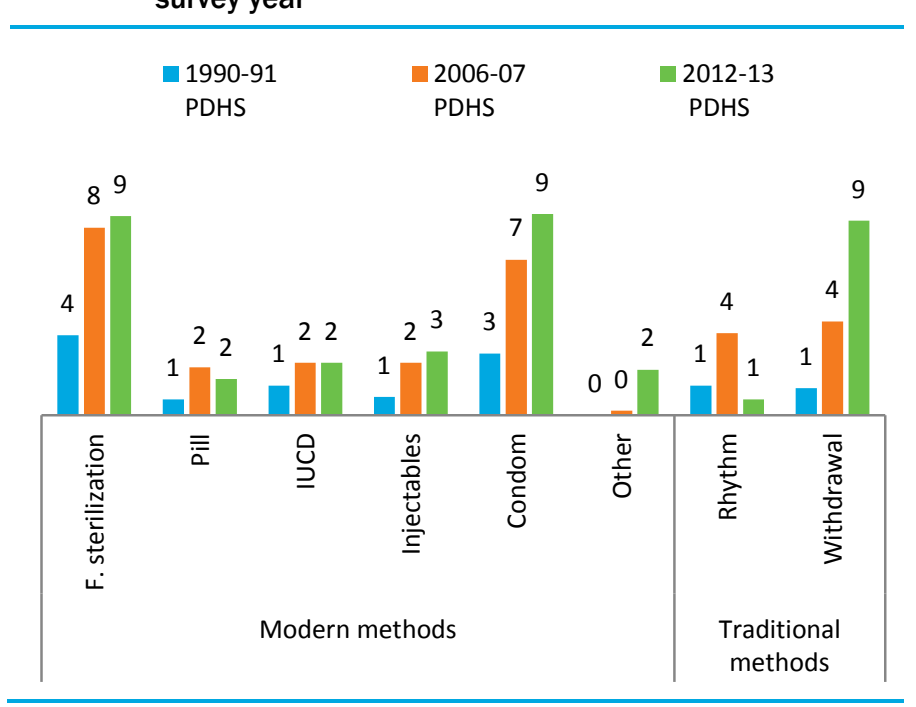

Source: Pakistan Demographic and Health Surveys

These trends indicate that overall, a quarter of women use withdrawal and another quarter use condoms, meaning that half of currently married women use couple-methods of family planning. This is very different from the rest of the South Asian region where female-methods are the most common forms of contraception (see below).
Table 2: Top three most common contraceptive methods currently used by country

\begin{tabular}{|c|c|c|c|}
\hline & $\begin{array}{l}\text { Most } \\
\text { common }\end{array}$ & $\begin{array}{l}2^{\text {nd }} \text { most } \\
\text { common }\end{array}$ & $\begin{array}{l}3^{\text {rd }} \text { most } \\
\text { common }\end{array}$ \\
\hline Bangladesh 1 & Pill (27) & Injections (11) & $\begin{array}{l}\text { Periodic } \\
\text { abstinence (7) }\end{array}$ \\
\hline India 2 & $\begin{array}{l}\text { Female } \\
\text { sterilization } \\
(37)\end{array}$ & Condom (5) & $\begin{array}{l}\text { Periodic } \\
\text { abstinence (5) }\end{array}$ \\
\hline Nepal 1 & $\begin{array}{l}\text { Female } \\
\text { sterilization } \\
(15)\end{array}$ & Injections (9) & $\begin{array}{l}\text { Male } \\
\text { sterilization (8) }\end{array}$ \\
\hline Pakistan 3 & $\begin{array}{l}\text { Condom } \\
\text { (9) }\end{array}$ & $\begin{array}{l}\text { Female } \\
\text { sterilization (9) }\end{array}$ & Withdrawal (9) \\
\hline
\end{tabular}

Source: Demographic and Health Surveys (1.2011, 2. 2005-06, 3. 2012-13)

However, the contraceptive method mix varies across Pakistan. Condoms are the most common choice of contraception in urban areas across all four provinces, while withdrawal is the second most common. In rural areas however, the choice of method is more varied across provinces. In rural Punjab, female sterilization and withdrawal are the most common choice. In rural Sindh, female sterilization is the most common method, while both condoms and withdrawal are almost absent. In rural $\mathrm{KP}$, withdrawal is the most common method, followed by condoms and injectables. The contraceptive method mix is more evenly distributed in rural Balochistan. The pill is used more commonly in KP and Balochistan than it is in Punjab and Sindh.

These differentials indicate that men in urban areas seem to share the burden of practicing contraception with their wives more than those from rural areas. Among those residing in rural areas, Sindhi men seem to be the least involved in sharing the burden of contraceptive use, as indicated by method choice. What these method choices reflect about gender dynamics, fertility regulation beliefs/perceptions/practices of communities and the provision of contraceptive services available will be discussed in detail in sections II and III. 


\section{Is high discontinuation contributing to low prevalence?}

Figure 3: Trends in contraceptive use 1984-2013

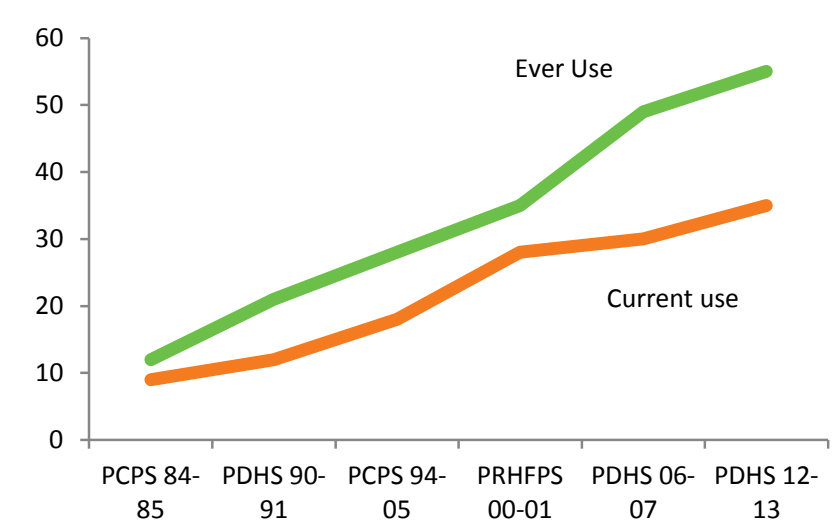

Sources: Demographic and Health Surveys (1990-91, 2006-07. 201213), Pakistan Contraceptive Prevalence Survey (1994-95) and Pakistan Reproductive Health and Family Planning Survey (2000-2001)

Current use of contraception remains low, yet more than half of Pakistani women have tried a contraceptive method in their reproductive lifetime. Even at a time when the CPR was showing signs of stagnation (PDHS 200607), ever use of contraception was increasing rapidly. The widening of the gap between the numbers of past users and current users indicates that a significant proportion of women use a method for a short time and discontinue use, falling back into those with unmet need. (Figure 3)

This is reflected in high discontinuation rates as well. More than a third of woman who started a contraceptive method in the five years preceding 2012-13 discontinued use within 12 months. One in every five women who used a contraceptive method discontinued use within a year due to a method related reasons, including side effects, method failure dissatisfaction with method, lack of access and affordability. The FALAH 2008-09 baseline survey, which contained comprehensive information on contraceptive episodes, shows even higher discontinuation rates (Mahmood and Naz 2012). The overall 12-month discontinuation rate for this sample was 45 percent, with 1 in every 4 women discontinuing because of method related reasons. Both datasets show that discontinuation rates are the highest for hormonal methods, injectables and the pill, followed by condoms and then traditional methods (Table 3). IUCD users have the lowest discontinuation rates.
Table 3: Twelve-month contraceptive discontinuation rates by method and survey

\begin{tabular}{lcc}
\hline & $\begin{array}{c}\text { FALAH Baseline } \\
2008-09\end{array}$ & $\begin{array}{c}\text { PDHS } \\
2012-13\end{array}$ \\
\hline Pill & 57 & 56 \\
IUCD & 24 & 26 \\
Injectables & 59 & 61 \\
Condom & 41 & 38 \\
Withdrawal & 38 & 32 \\
\hline
\end{tabular}

Side effects are the most common reason for discontinuation of modern methods (injectables and pills) while contraception failure is the most common reason for condom and traditional methods. (Figure 4) Method failure accounts for 15 to 18 percent of discontinuation (PDHS 2012-13; Mahmood and Naz 2012).

Figure 4: Reasons for discontinuation by method

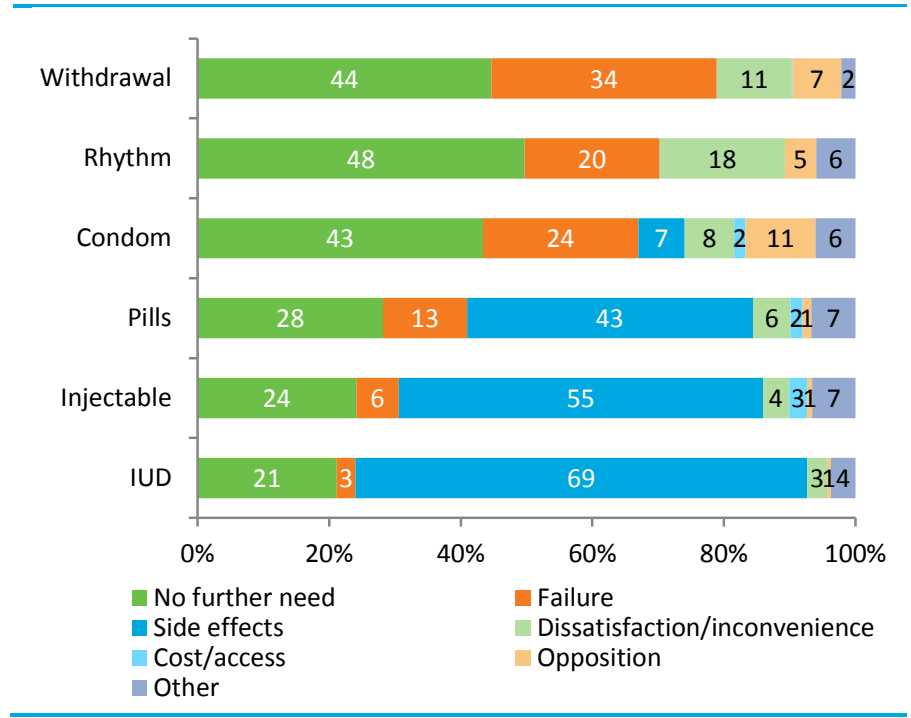

Source: Mahmood and Naz 2012

Both data sets show that method failure rates are the highest for withdrawal users and condom users, followed by women on the pill and those using the rhythm method. (Figure 5) Withdrawal and condom users account for approximately half of current and ever users of contraception, implying that an extremely large number of women are at risk for unwanted pregnancies. Unsurprisingly, contraceptive discontinuation has been found to be one of the factors leading to the large estimated number of induced abortions in Pakistan (Rashida et.al 2013; Sathar et.al 2013). 
Figure 5: 12-month method failure rates by method and data source

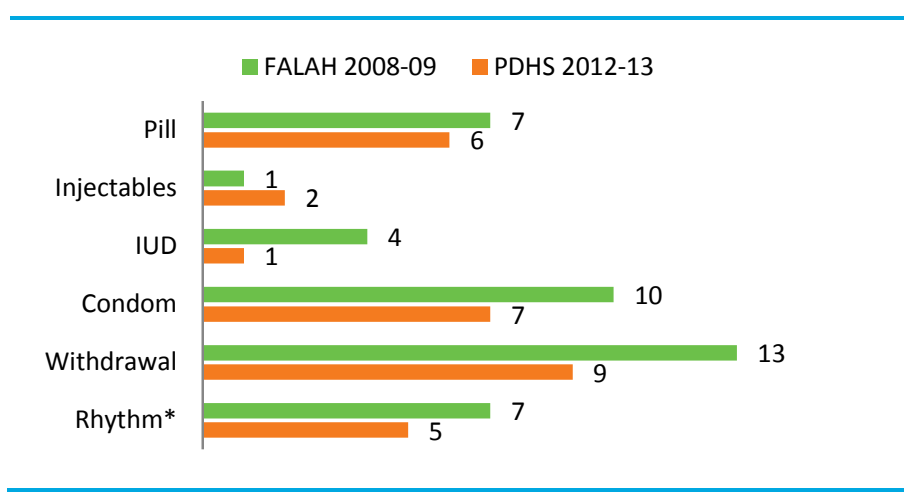

* Rhythm method includes other methods such as LAM and implants for PDHS 2012-13

Pakistan has one of the lowest contraceptive prevalence rates but highest discontinuation rates in comparison to most other developing countries (Mahmood and Naz 2012). Non-fertility related discontinuation rates for modern methods (pill, IUCD, injectables) are higher than India or Bangladesh's rates, and Pakistan has lower switching rates than other countries with comparable levels of discontinuation. More Pakistani women discontinue using these modern methods because of method failure or experiencing side effects than their South Asian counterparts. Mahmood and Naz's (2012) analysis shows that eliminating discontinuation due to side effects and method failure would increase continuation rates (at one year) by 10 percent and 6 percent, respectively.

Contraceptive failure rates reflect the effectiveness of the method as well as how reliably women use the method, which is closely linked to knowledge and the information provided at the time of method adoption. Discontinuation due to side effects is also related to counseling both before and after adoption of method as well as the availability of alternative methods to be able to switch to. High discontinuation due to such method-related reasons reflects gaps in access to comprehensive method-specific information and counseling on these methods as well as a limited mix of methods to choose from. These factors will be examined in Section III on quality of care.

\section{Is there substantial demand for family planning?}

Population Council (2014) in its report "Prioritizing Family Planning for Achieving provincial Maternal Child Health and Development Goals" argued that the majority of men and women across all provinces of Pakistan express their desire for fewer and better-spaced children. Combining contraceptive prevalence rates with the proportion of women who desire to use contraception for spacing or limiting, but are currently not using any method (those with unmet need), illustrates the existing high proportion of Pakistani women with a demand for contraception. At the national level, 55 percent of currently married women express the desire to practice contraception, as measured by a desire to have no more children or not have another child for the next two years. Of these women, one-third are not currently using contraception. Of the 64 percent that are practicing family planning, three-quarters are doing so with the use of modern methods.

Examining total demand (met + unmet) for family planning across regions uncovers interesting patterns. Urban-rural differences in total demand are in the expected direction - there is greater demand in urban areas than rural areas. However, this is not the case for provincial variations. Contrary to expectations, urban areas in KP (rather than Punjab) have the highest demand for contraception and rural areas in Sindh (rather than Balochistan) have the lowest demand for contraception. (Figure 6) Of course, a greater proportion of this existing demand is met in Punjab than in KP. Likewise, the proportion met is greater in Sindh than in Balochistan.

At the national level, one in every five (20 percent) married women of reproductive age (MWRA) has unmet need for contraception (PDHS 2012-13). Down from 25 percent in 2006-07, this number is still among the highest in the region (Chaudhary 2001). Using statistics from 2006-07, Khan and Khan (2012) estimated that out of nearly 24 million women of reproductive ages, approximately 7 million were using a contraceptive method. Of the remaining 17 million, six million had an unmet need for contraception; they want to limit or space births, i.e. practice family planning, but are not doing so. Given the increase in Pakistan's population, the number of women with unmet need is not likely to have declined significantly despite the reduction in unmet need.

Younger women (ages 20 - 35) have greater unmet need for contraception, much of which is for spacing births. Rural areas have higher unmet need, as do women from Balochistan (31 percent), followed by KP (26 percent) and then Sindh (21 percent). These differentials in unmet need can be broken down into spacing and limiting by place of residence across provinces (see Figure 6). As is evident from the figure, unmet need for spacing is greater in Balochistan and rural Sindh, whereas for the other areas, it is higher for limiting births. Given the lower contraceptive use and higher fertility rates in these regions, this may point to differences in preferred family size or the social acceptability of contraceptive use as a means to limit versus space births. 


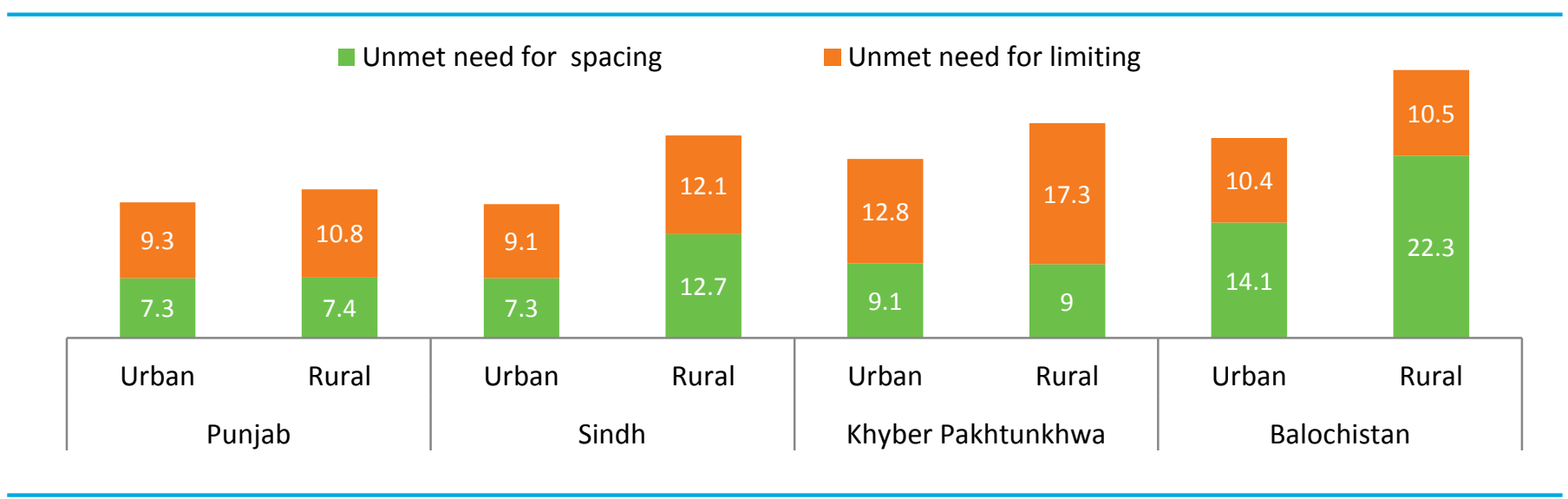

Source: PDHS 2012-13

Unmet need in Pakistan is closely associated with abortions, neonatal deaths and unwanted pregnancies. According to UNFPA, one in three of all pregnancy and childbirth related deaths can be avoided if women who want to use contraception have access to it. However women with unmet need are not the only ones at risk of unwanted pregnancies. Given the high rates of contraceptive discontinuation, many of the women currently using contraception - those with met need -- are likely to discontinue the method later. Some of these women will experience method failure and become pregnant, some will get pregnant in the time it takes to find another method, and others will remain nonusers at the risk of unwanted pregnancy after discontinuing a method. Using data from 14 districts of Pakistan, Jain et. al (2014) find that women with met need contribute 37 percent of unwanted fertility. Contraceptive discontinuation among current users will result in thousands of future cases of unmet need (Jain et. al 2013).

Close to half of women not using contraception (44 percent), do not intend to use a contraceptive method in the future (PDHS 2012-13). While this proportion has remained unchanged for five years, the proportion intending to use contraception in the future has declined from 50 percent to 40 percent. More women are unsure about their intention to use family planning in the future than they were in 2006-07.
Why are women not using contraception when they desire to?

The 2006-07 PDHS asked women why they did not intend to use contraception in the future. More than half these women had fertility-related reasons such as the desire to have more children, fatalistic attitudes about fertility, and low risk of pregnancy (infrequent sex, menopause, among others). Among non-fertility related reasons, opposition to use (by respondent, husband, and religion) and health concerns (including fear of side effects) were the two most common. Another study, surveying women from 15 districts of Pakistan, found husband opposition and fear of side effects to be the two most common reasons for nonuse as well (FALAH 2012).

Over the last two decades, multiple studies, both academic and programmatic, have been conducted to understand why the fertility transition in Pakistan began so late, and once started, why it has been so slow to reach levels comparable to those in neighboring countries. While several of these studies have employed statistical techniques using existing survey data to capture sophisticated obstacles to contraceptive use, others have collected their own data (quantitative and qualitative) to obtain more in-depth and comprehensive information on men and women's reproductive intentions and behaviors. Yet others have focused on analyzing programmatic and policy initiatives to get answers.

Starting from the 1990s, several studies have found that social acceptability plays a significant role in determining whether a Pakistani woman uses contraception (Casterline et. al 2001; Stephenson and Hennick 2004). Husband's disapproval (Mahmood and Ringheim 1996; Casterline et. al 2001; Agha 2010) and religious opposition (Hashmi et. al 1993; Mahmood and Ringheim 1996; Mir and Rashida 2013) have been the two most 
commonly mentioned aspects of social acceptability. Given the recurrence of husband's approval as a determinant of contraceptive use, other studies have found a strong association between inter-spousal communication and contraceptive use (Mahmood and Ringheim 1997). Another major explanation for the low uptake of modern contraceptive methods is centered on the status of women, seen through a strong son preference (Hussain et. al 2000), or the link between women's autonomy and mobility and contraceptive use (Sathar and Kazi 1996; Sathar and Kazi 1997; Jejeebhoy and Sathar 2001; Saleem and Bobak 2005; Mumtaz and Salaway 2005). Reflecting trends from survey data, several studies find the fear of side effects or related health concerns to be a major obstacle in the uptake of modern contraceptive methods as well (Hashmi et. al 1993; Nishtar et. al 2013).
And finally, another recurring theme in this literature focuses on supply-side factors, mainly the overarching importance of access to, or availability of, affordable and quality family planning services (Rukanuddin and HardeeCleveland 1992; Shelton et. al 1999; Fikree et. al 2001; Hennick and Clements 2005; Kamran et. al 2013). The next section of this report looks at the evidence for the social and cultural determinants; the fear of side effects are directly related to quality of service provision and counseling, therefore it will be examined more closely in section three. 


\section{Section 2: Unpacking the demand-side obstacles to contraceptive use}

\section{Universal knowledge of contraception, education and the status of women}

"Knowledge of contraception is universal in Pakistan" is the key finding that the chapter on family planning begins with in the final report of PDHS 2012-13. More than 96 percent of currently married men and women have heard of at least one method of contraception. More than 80 percent of women have heard of female sterilization, IUCD, injectables and the pill; two-thirds have heard of withdrawal and LAM; close to half have heard of male sterilization and rhythm method; a third have heard of implants' and only a quarter of women about emergency contraception. Men are more likely to know about condoms and withdrawal, but less likely to know of LAM, IUCD, implants and emergency contraception. Measuring universal knowledge as having heard of at least one method is misleading. Given how demand for contraceptive method changes over the course of a woman's reproductive lifecycle, with increasing parity and age, and how it varies across cultural settings, knowledge of one method might not meet any of those needs.

More importantly, in order for knowledge of a method to translate into use of that method, it has to extend beyond just having heard of the method. Knowledge of how the method works, its side effects, where it is available and how much it costs are all critical to a woman's decision to use that method. Mahmood and Ringheim (1996) in their analysis of the determinants of contraceptive use in Pakistan found that knowledge of source of contraceptive method was one of the three major factors predicting contraceptive use among married women. Another study found that while knowledge regarding availability and affordability of contraceptives was nearly universal in a low-income urban setting, knowledge regarding appropriate use of method was poor, especially among women, and even among those men and women currently using that method (Fikree et. al 2005).

The misplaced assumption of women's universal knowledge of contraception is reflected in the lack of comprehensive questions regarding knowledge in most contraceptive use surveys. Within the literature on contraceptive use, most studies that do include detailed discussions on knowledge-related factors focus primarily on young women (Nishtar et. al 2013). Future studies should place greater emphasis on gaining a more indepth and meaningful understanding of the level of contraceptive knowledge among Pakistani women and men. Lack of comprehensive knowledge is a likely contributor to the wide fear of side effects and high discontinuation rates (discussed in further detail in the next section).

Given the simplistic measure of knowledge available in survey data, it is not surprising that most studies do not find a significant association between knowledge and contraceptive use. In so far as education levels function as a proxy for knowledge, we find that access to information is an important factor in determining use. Contraceptive use increases dramatically with educational attainment. According to the latest PDHS, the CPR for women with no education is 30 percent, compared to 44 percent for women with higher education. Women with higher education are also the most likely to have their demand for family planning satisfied. Studies consistently find education to be a significant determinant of contraceptive use, even when moderating effects of other demographic factors such as residence, wealth, age, and parity are accounted for (Sathar \& Mason 1993; Jejeebhoy 1995; Alam et. al 2003; Soomro \& Mahmood 2004).

While much of the effect of education on contraceptive use works through its effect on motivation to regulate fertility, some is likely to be due to the fact that educated women have greater access to information regarding contraceptive methods. In fact, education differentials in exposure to family planning messages lend support to both these mechanisms. One in five women with higher education has read of family planning messages in newspapers and magazine - this proportion is higher than for women residing in urban areas or those from the wealthiest households (PDHS 2012-13).

Of course women's educational attainment levels are also indicative of the status of women (Jejeebhoy 1995; Mason 1997), which is another factor frequently mentioned in discussions on Pakistan's low contraceptive use. Several articles have highlighted the link between the low status of women (measured via autonomy) and low contraceptive use in Pakistan. Autonomy in most of these studies is operationalized through a woman's decision-making power within the 
household and/or mobility (Sathar and Kazi 1997; Jejeebhoy and Sathar 2001; Saleem and Bobak 2005).

Findings from these investigations are not conclusive; some find a strong correlation between autonomy and contraceptive use (Sathar \& Kazi 1997) while others find none, and yet others find significant effects for one aspect - decision-making - but not the other - mobility (Sathar and Kazi 1997; Fikree et. al 2001; Saleem and Bobak 2005). Mumtaz and Salaway's work (2005) highlights how mobility as a barrier to uptake of contraception varies between types of services, between groups of women, and between communities. It can operate differently in different contexts, in some cases it can have a direct relationship with contraceptive uptake, in others it operates through other pathways like increased access to information, and often it is just a proxy for other important dimensions of a woman's position.

Similar to India, but unlike Bangladesh, Saleem and Bobak (2005) find that autonomy does not mediate the link between education and contraceptive use in Pakistan. Dharmalingam and Morgan's (1996) analysis of two Indian villages also demonstrates that the relationship between education, autonomy and contraceptive use is context specific. Contraceptive prevalence was high in both villages, one with high female mobility but low education and the other with high education but low autonomy. These studies highlight the complex set of constraints that fertility regulation decisions operate under. Individual contraceptive behavior is determined by the interplay of microcharacteristics and contextual/macro-level structures.

Does contraceptive method choice adhere to cultural norms or just reflect availability of methods? In order to understand the structural constraints that men and women face when making decisions related to contraceptive use, section III of the report examines the status of the supply of contraceptives more closely.

\section{Social opposition}

Lack of social acceptability of fertility regulation is perhaps the most frequently mentioned cause for low contraceptive use in Pakistan. Social concerns were the most common reason for not using contraception given by nonusers in the 2006-07 DHS data. Given the lack of autonomy and restricted mobility that married women have in several parts of Pakistan, it is not surprising that husband's disapproval is the major pathway that social costs operate through. Both DHS and FALAH endline data reflect this; husband's opposition is the most cited nonfertility related reason for not using contraception. Even when other factors are accounted for, husband's approval is found to be one of the main factors in determining contraceptive use (Casterline et. al 2001; Agha 2010).

The majority of data on the reasons for nonuse, or the obstacles to contraceptive use more broadly, are based on women's responses, reflecting their perceptions of husbands' attitudes more accurately than the actual views of husbands. Studies that utilize the limited data on both husband and wives' attitudes and perceptions find that in reality wives are often incorrect about the views of their husband's on contraception. According to the FALAH baseline data on 29 districts of Pakistan, a quarter of women reported that their husbands disapproved of practicing FP. However, husbands' own reports of FP attitudes showed that almost two-thirds (61 percent) of these women incorrectly perceived husband disapproval (Zaidi and Naz 2011). Spousal communication reduces the discrepancies between perceptions and reality. The same analysis finds that 90 percent of wives correctly perceive husband's attitude to FP when there is spousal communication, compared to 70 percent among those who have not discussed FP with their spouse. Unsurprisingly then, there is a positive association between spousal communication regarding family planning and contraceptive use in Pakistan (Mahmood and Ringheim 1997).

Women's choice of contraceptive method also sheds light on gender dynamics and the role that men play in practicing contraception. As mentioned earlier in this report, half of the women currently practicing contraception, use couple-methods that require the active involvement and cooperation of men (withdrawal and condoms). The high prevalence of couple-methods reflects the gender dynamics of a patriarchal society like Pakistan, where women have relatively little decisionmaking power and men maintain control over reproductive behavior. At the same time it also implies that men are not as opposed to contraception as they are made out to be. A qualitative study on Punjabi men's attitudes towards contraception finds a growing concern about the financial challenges of raising large families among men; men demonstrate the readiness to practice 
family planning and express the need for the services to be able to do so (Kamran et. al 2013).

The increasing willingness of men to practice contraception and high prevalence of couple-methods highlight the need for research and programs to be less women-centric and include men in their analysis and interventions to address low contraceptive uptake.

Religious opposition is another factor commonly presented as a major contributor to the social costs of practicing contraception in Pakistan (Hashmi et. al 1993; Shah and Cleland 1993; Mahmood and Ringheim 1996;

Casterline et. al 2001; Pasha et. al 2001). Men in rural areas often cite religion as a reason for not using contraception (Ali and Ushijima 2004); and misconceptions about the permissibility of family planning in Islam have led to ambiguous attitudes among couples, service providers and policy makers (Mir and Rashida 2013). Failure to obtain religious leaders' endorsement has contributed to Pakistan's family planning program's limited success.

However, looking over time, we find that the proportion of women citing religious opposition as their reason for not using contraception declined significantly between 1991 and 2007 and is no longer the most common reason in urban as well as rural areas (Population Council 2010). More importantly, the high (and increasing) prevalence of induced abortions in Pakistan undermines the legitimacy of religion as an obstacle to contraceptive use. The impermissibility of abortions is significantly less ambiguous (than that of FP) in the common interpretations of Islamic law; moreover, abortions are a strong cultural/religious taboo and are permissible only to save a woman's life and to provide 'necessary treatment' (United Nations 2002). Yet women continue to seek abortion services, even with the additional health risks resulting from unsafe conditions and unskilled providers.
It is extremely unlikely that religious opposition is the driving force behind women's decision not to use contraception to achieve their desired reproductive goals, when they frequently resort to abortions instead. There is evidence of the weak role of religious opposition on fertility behavior in the findings from the in-depth study on Punjabi men (Kamran et. al 2013); hardly any men mention religion as a reason for not using contraception, and interestingly, those who did were actually using a contraceptive method.

Future research needs to distinguish between superficial, and perhaps socially desirable reasons, from those that actually impact behavior, and assess the relative strength of reported obstacles stated by men and women.

This section of the report discussed the demand-side factors that contribute to low uptake of modern contraceptive methods. However, it is equally important to look at the supply-side factors as they impact the structural and material constraints that individual preferences operate under. The next section looks at these factors more closely. 


\section{Section 3: Supply-side factors}

\section{Access to affordable and quality methods}

Relying on large-scale survey based responses on reasons for nonuse can lead to an incomplete and possibly inaccurate understanding of the obstacles to contraceptive uptake. This is perhaps best demonstrated by the relatively infrequent reporting of contraceptive availability and monetary cost as reasons for nonuse by Pakistani women. In order to determine the significance of access to affordable and quality contraceptive methods, we need to look more closely at shifts in contraceptive behaviors, especially in response to changes in the supply environment.

Sharp and persistent wealth differentials in contraceptive use suggest that access and monetary costs do play a role in women's decision to use modern contraception even if they are not common cited as reasons for nonuse. A study by the Population Council (2010) demonstrates that wealth differentials are more strongly correlated to current use than education, and distance to the nearest FP service outlet for the poorest quintile of houses is almost double the distance for the richest households (Population Council 2010). The monetary costs of contraception that disproportionately impact women from poor households are exacerbated by the cost of travel to reach facilities. Several studies have now shown that the improving access to contraception via increases in service outlets and outreach programs reduces unmet need for family planning (Shelton et. al 1999; Fikree et. al 2001; Mahmood 2012).

A study of public sector health facilities in 14 districts of Pakistan found that one in four women seeking FP services spent more than an hour travelling to the facility. Almost all women (90 percent) coming to the facilities for FP services were accompanied by someone, most often a female relative (43 percent) (Mahmood et. al 2012). The geographic spread of family planning programs in most of the parts of Pakistan is limited; access remains a critical issue. Women's restricted mobility intensifies the issues of physical distance to facilities providing family planning services, particularly in rural areas.

Availability of family planning methods and services

According to PDHS 2012-13, where women obtain modern methods from varies by location and type of method. In rural areas, the public sector, comprising mainly of RHSCs and LHWs, is the main source of contraceptive methods; in urban areas the main source is the private sector, which includes private hospitals, clinics, pharmacies and chemists. (Figure 7)

Figure 7: Source of Contraception by place of residence
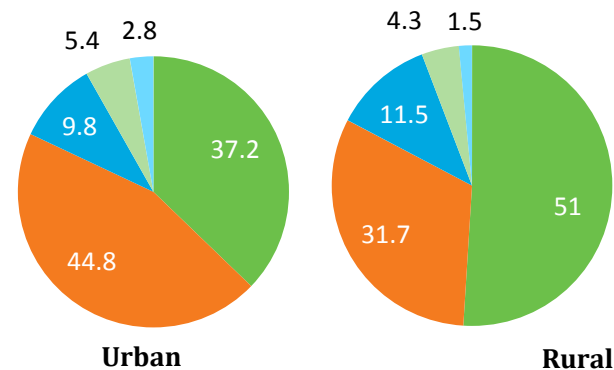

Public Sector

Private Sector

- Shop

Other

Don't know

Rural

Source: PDHS 2012-13

Two-thirds of all female sterilizations take place in public hospitals and the remaining in private hospitals and clinics. A third of pill users obtained the method from pharmacies or shops, while another 30 percent from LHWs. Private hospitals and clinics were the source for a third of IUCD users; the public sector was the source for half of IUCD users, with 30 percent by public hospitals alone. (Figure 8) The proportion of women receiving injectables were evenly divided between RHSCs, LHWs and private hospitals/clinics, with each type of provider accounting for around one-fifth of users. More than half of condom users obtained the method from chemists or other shops. Within the public sector LHWs were the primary source of condoms, but only accounting for 14 percent of users.

\section{Figure 8: Distribution of providers for specific modern} contraceptive methods in Pakistan

Public Sector $\square$ Private Sector Shop Others

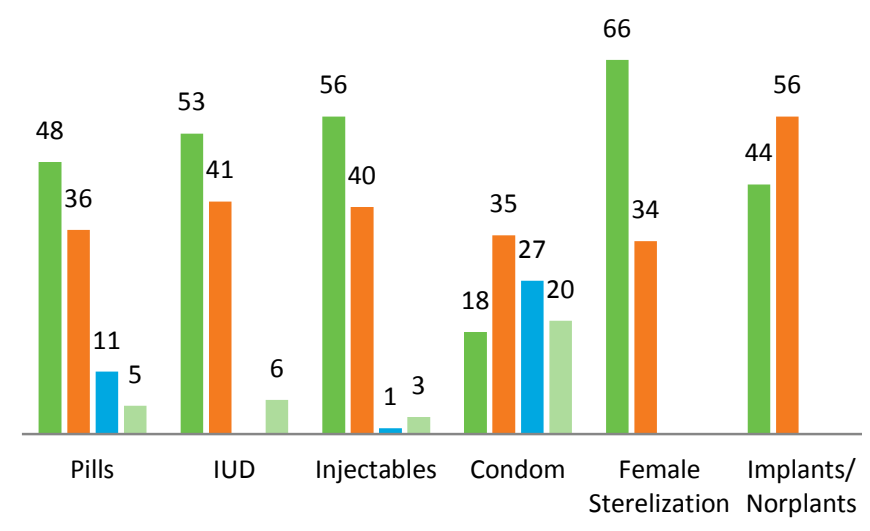

Source: PDHS 2012-13 
The public sector continues to provide the bulk of family planning services in Pakistan; 54 percent of FP services come from the public sector. Although the private sector is the primary provider of health services in Pakistan generally, it only provides 20 percent of the share of family planning services, with non-governmental organizations providing the remaining 26 percent of services (Hamid and Stephenson 2006). Data on static health facilities from 34 districts of Pakistan collected under the FALAH project show similar distributions. Twothirds of public sector facilities provide any clinical FP methods, compared to around one-third of private sector facilities

A situation analysis of public sector health facilities in 14 FALAH districts also found that only two-thirds of these facilities had at least one contraceptive method in stock (Mahmood et. al 2012). (Figure 9) Among these facilities, close to 35 percent had inadequate supply of condoms and pills, and around 45 percent had inadequate supply of injectables and IUCDs. A contraceptive stock analysis of public sector service delivery points (SDPs) was conducted in 15 districts of Pakistan that received contraceptive supplies from USAID through the DELIVER project (USAID/DELIVER 2013). The results of this analysis found that the supply of contraceptives at health facilities was highest in districts in Sindh, followed by Punjab and KP. The report also found that LHWs have the lowest supply of contraceptives, with only a third of the LHWs in Sindh and Balochistan having even one contraceptive method. This is alarming, given that among women currently using reversible modern contraception, LHWs were the source of method for half the women who obtained the method from the public sector (PDHS 201213).

Figure 9: Percentage of facilities with at least one contraceptive method available

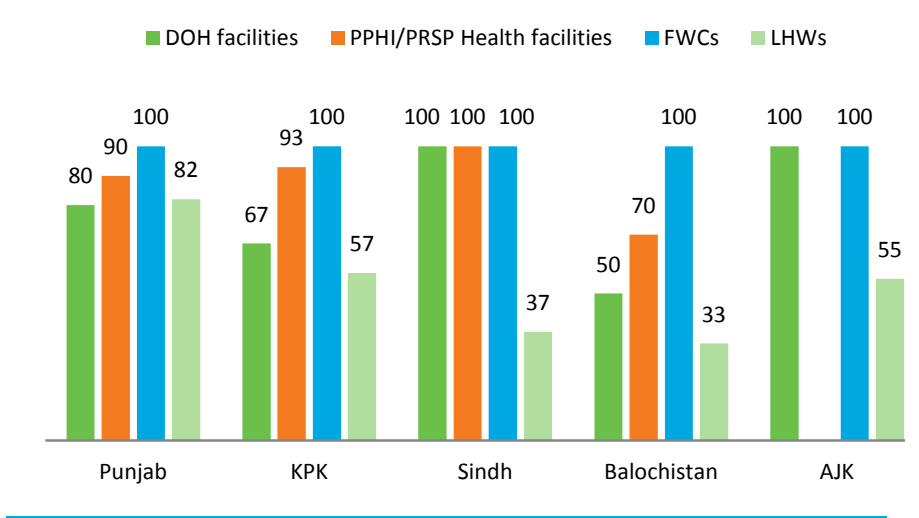

Source: USAID/DELIVER PROJECT, 2013

\section{Poor quality of care}

An important factor determining contraceptive uptake and continuation is the level of quality of care of family planning services (Mahmood et. al 2012). The quality of care in family planning programs can be gauged from several factors including choice of contraceptive methods, information given to patients, technical competence, and interpersonal relationships (Bruce 1990; Jain 1989). Unfortunately, as measured by information given to clients and provider attitudes and knowledge, the quality of care in family planning services remains very low in Pakistan.

\section{Lack of counseling on methods}

Most Pakistani women using a modern contraceptive method did not receive adequate information or counseling on the various contraceptive methods they could choose from, their side effects or what to do when experiencing side effects. According to PDHS 2012-13, among current users, two-thirds were not informed about side effects or issues with their method of choice, and around 72 percent were not told what to do in case of side effects or which other method they could switch to. The situational analysis of public health facilities in 14 FALAH districts showed similar trends. One in every three providers reported that they did not counsel FP clients on possible side effects, and more than 90 percent did not inform clients about how to manage side effects or possible methods to switch to (Mahmood et. al 2012). The lack of proper counseling is found in private sector facilities as well. According to the private provider study, only six percent of private providers included management

of side effects as one of the topics they would discuss with FP clients (Haque et. al 2012). This proportion increases to just 10 percent when considering only female doctors and LHVs, the primary providers of FP services.

High rates of discontinuation are not surprising when women are given inadequate information to manage side effects and are not assisted in making informed choices about which method to use. The importance of side effects is reflected in the method-specific reasons for discontinuation in the PDHS 2012-13 as well. Almost two-thirds of women who tried using an IUCD in the last five years discontinued because of health concerns and side effects. This was true for 53 percent of users who tried injectables and 45 percent of users who tried the pill. Among current users of modern contraception, 
around half the women using injectables reported experiencing side effects. A quarter of women using the IUCD or the pill experienced side effects. The FALAH survey also asked traditional method users and past users of contraception their reasons for not currently using a (modern) method, for both sets of women fear of side effects (and the experience of side effects for the latter group) was the most common non-fertility related reasons given (Mahmood 2012). Information on the duration of effectiveness is also critical to ensure lower method failure rates. Results from one study showed that method failure rates were lower for pill and injectable users who received such information than those who did not (Mahmood and Naz 2012).

Bad experiences with side effects for ever users have a spillover effect on nonusers as well when women share these experiences with others. Several of the studies analyzing women's reports of obstacles to use find that health concerns related to contraceptive use - mainly a fear of side effects - are one of the main explanations for nonuse of contraceptive methods (Hashmi et. al 1993; Stephenson and Hennick 2004; Sathar and Zaidi 2011; Nishtar et. al 2013). According to the PDHS 200607 , health related concerns were the second most frequently reported reason (after social opposition) for not currently using a method by married women. Fear of side effects was the highest non-fertility related reason reported for nonuse in the FALAH baseline survey (200809) and the endline survey (2011-12) showed that even after several programmatic interventions it was the second-highest reason. Men share the widespread fear of side effects as well. The qualitative study with Punjabi men (Kamran et. al 2013) found that almost all participants of the study mentioned side effects experienced by women, particularly irregular bleeding, obesity and anemia, during in-depth discussion on obstacles to using modern contraception.

The widely prevalent health concerns, in the form of both fears and experiences, is partly an indicator of low levels of comprehensive knowledge of modern methods. More IEC interventions to improve method-specific knowledge and better counseling on the part of service providers are critical for addressing couple's health concerns and increasing the uptake of modern contraception in Pakistan. Hamid and Stephenson (2006) found that even just displaying IEC materials at the facility alone increased the likelihood of contraceptive uptake.
Provider attitudes, knowledge and technical skills Providers' attitudes to family planning are ambivalent and their motivation to provide FP services remains weak. In the private provider study, Haque et. al (2012) found that 38 percent of providers were not providing family planning services because they did not consider family planning an important issue or thought that other health issues were more important. An additional 11 percent were afraid of losing goodwill in the community and 6 percent believed FP was against culture. Among those who discontinued providing FP services, 12 percent did so because they thought it was against religion and 9 percent preferred spending time on other health issues they considered more important.

Providers also have misconceptions about the various family planning methods available. 35 percent of private providers thought that one of the three hormonal methods may lead to infertility; 30 percent thought they may cause to cancer; and 34 percent thought injectables, have profound side effects on a woman's body, 25 percent thought pills do, and 20 percent thought IUCD does (Haque et. al 2012).

These findings point toward a highly significant need for educating and training providers on modern contraceptive methods. As well as providing them with the technical and interpersonal skills to address side effects and counsel clients on effective method use and management of side effects. There is also need for a larger scale assessment of provider attitudes and knowledge.

\section{Shortcomings of the public sector}

Neglecting to involve religious leaders in supporting the FP program

The misperception of birth control as illegal in Islam has weakened the family planning program in Pakistan.

These misperceptions are detrimental to contraceptive uptake, more because of their impact on service providers, politicians and policy makers than their effect on the demand for family planning as shown in the previous section. Among private providers from $34 \mathrm{FALAH}$ districts, almost all MBBS doctors and LHVs believed that birth spacing was allowed in Islam, but a quarter of them believed that Islam did not approve of family planning more broadly. Dispensers were even more likely to believe that Islam does not approve of birth spacing and family planning, 20 percent and 33 percent respectively 
(Haque et. al 2012). Politician and policy makers also hesitate to push the family planning agenda because of ambivalent attitudes towards family planning and fear of religious backlash.

Muslim countries like Bangladesh, Egypt, Indonesia, Iran, and Tunisia obtained endorsement for family planning from religious scholars very early on and this has contributed to the success of their family planning programs (Shaikh et. al 2013). For example, Iran launched its national FP policy endorsed by the supreme leaders in 1989. These leaders collaborated with health practitioners to promote family planning through the media as well as mosques. These interventions by Iran contributed to rapid rise in CPR from 37 percent to 73 percent within two decades (Mir and Rashida, 2012). Bangladesh invested in educating and training Muslim clergy for the purpose of family planning promotion. Egypt's Program succeeded with the help of scholars at Al-Azhar University, the most reputable and followed Islamic center in the country.

Women residing in communities with religious leaders that promote family planning have been found to be more likely to use contraception in the Pakistani setting as well (Raza et. al 2012). However, Pakistan's family planning program has failed to seek endorsement from its religious leaders and scholars and is only now starting to acknowledge the significance of this oversight and take action to address it. Drawing lessons from these countries, Pakistan needs to create a family planning policy that involves religious leaders and gains their support towards promoting and increasing contraceptive use in Pakistan.

\section{Family planning services as a priority for LHWs}

One of the primary responsibilities of the Lady Health Workers program is to provide family planning services to communities, particularly in rural, underserved areas. Evaluations of the LHW program declared the program a success in uplifting FP services; they were also responsible for the increased likelihood of contraceptive uptake by 1.5 times in rural areas during the 1990s (Douthwaite 2005; Hafeez et. al 2011). However, the latest evaluation of the program found a decline in the number of households utilizing the services of LHWs between 2000 and 2009. The contraceptive prevalence rate in LHW served areas only increased by one percentage point during this time period (OPM 2011).
Relatedly, PDHS 2012-13 results find almost one-third of currently married women living in rural areas did not know of an LHW in their area. Exposure to LHWs is much lower in rural KP and Balochistan, only 54 and 29 percent of women in these two regions knew of an LHW in their community. Among those women who did know of an LHW, only seven present received contraceptive supplies from one. This proportion was lowest in Balochistan and highest in KP. This indicates that women in KP rely on LHWs to supply them contraceptives yet many of them reside in areas where no LHW is present. Among current users of modern contraception, LHWs were the source for 29 percent of pill users, 21 percent of injectable users, and 14 percent of condom users (PDHS 2012-13).

Contraceptive stock analysis study shows that LHWs frequently have very low supplies of the three methods they are meant to provide, particularly in Sindh, Balochistan and KP. While 70 percent of LHWs in Punjab had a supply of injectables, only around a quarter in KPK and Sindh did while none of the LHWs in DELIVER districts of Balochistan had injectables. The proportion of LHWs with a supply of pills (POP and COC) (Figure 10) was highest in KP and Punjab (USAID/DELIVER 2013).

\section{Figure 10: Percentage of LHWs with supply of modern} methods

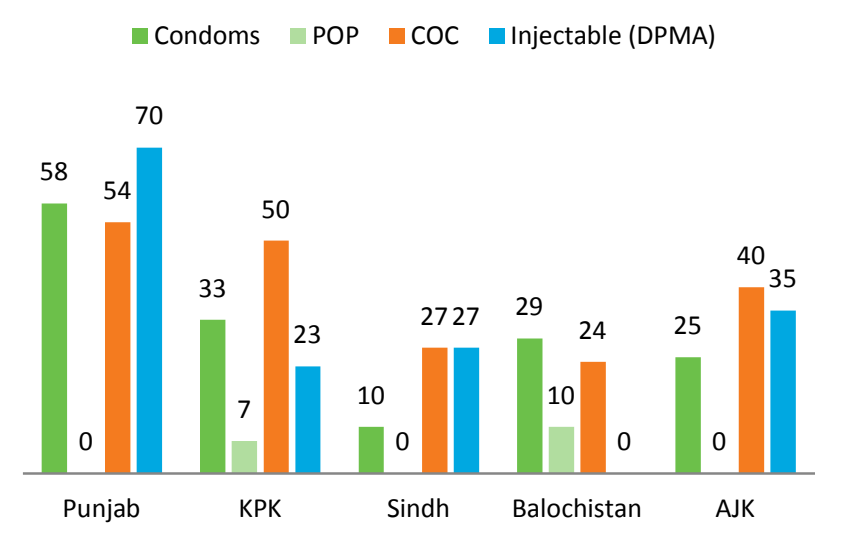

Source: USAID/DELIVER PROJECT, 2013

Exacerbating the problem of insufficient supply of contraceptives further is the increasing burden on LHWs to provide other primary health care services to communities (Islam et. al 2002). LHWs have been given additional tasks related to immunization, administering polio doses, TD dots, malaria control and other health campaigns (OPM 2011). As a result, LHWs are over- 
burdened and often unable to prioritize family planning services.

NGOs and private sector contribution to the uptake of contraceptive use

As mentioned earlier, the private sector (private medical facilities, chemists and shops) and NGOs were the source of modern methods for 45 percent of current users of contraception in the PDHS 2012-13. Nongovernmental organizations' contributions towards supporting FP services and assisting the public sector in filling gaps remains critical; they have 26 percent of the market share of family planning services, more than the private sectors' 20 percent. The Family Planning Association of Pakistan (FPAP) alone has more than 540 service outlets that deliver 10 to 12 percent of Pakistan's family planning services (Hamid \& Stephenson 2006). Marie Stopes Society is another NGO providing family planning services; it has 428 clinics, 82 services delivery centers and one mother and child health centre, providing services in 73 districts of Pakistan and two subdivisions of FATA, covering 70 million people in the country.

\section{Successful interventions to scale-up}

Non-government organizations also play a role in improving the FP services in Pakistan by providing evidence-based information on successful programs, interventions and strategies for the government to scale up. The international organization Population Council implemented the five-year USAID funded Family Advancement for Life and Health (FALAH) project in 20 districts across Pakistan. The main aim of this project was to lower the unmet need for family planning by improving access to services and uplift the quality of health care by public sector. For this purpose 10,534 health personnel were trained. The training module also included an Islamic perspective of family planning, which was developed with the consensus of religious scholars and health officials. At the end of the project the results of this training were positive in terms of increasing the use of contraceptive use for family planning by creating awareness among spouses. The CPR in FALAH districts increased from 29.4 percent to 37.9 percent over the span of five years. This increase of 8.5 percentage points during the project interval is considered to be the direct result of FALAH interventions.

\section{Social marketing by the private sector}

The private sector has generally adopted a social marketing approach, in which commercial marketing techniques are adapted to the provision of family planning

services in an attempt to make products and services available and affordable to low-income groups. The major player in the private sector is Green Star Social

Marketing. Green Star offers a range of socially marketed products and services for family planning, the most popular of which are condoms and pills. Green Star's products are distributed through a nation-wide network of over 7000 franchised clinics, 75,000 retail outlets and community-based distribution. The social franchising and voucher schemes by both Green Star and Marie Stopes have proven to be successful in increasing contraceptive uptake (Hennick et. al 2002; Agha \& Meekers 2010; Shah et. al 2011; Azmat et. al 2013).

However, the private sectors' contribution to family planning services still remains limited compared to its contribution to the health sector at large, 20 percent versus 70 percent (Hamid \& Stephenson 2006).

Moreover, private sector family planning services remain unaffordable for a large subgroup of the Pakistani population (Agha 2000). This can be seen in the breakdown of source of method by household wealth status using the PDHS 2012-13 data as well. While the majority of currently using women from the richest households get their contraceptive method from the private sector (including shops), the majority of women from the poorest households still go to public sector facilities to obtain contraceptive methods. (Figure 11)

\section{Figure 11: Source of contraceptive method of current} users by household wealth quintiles

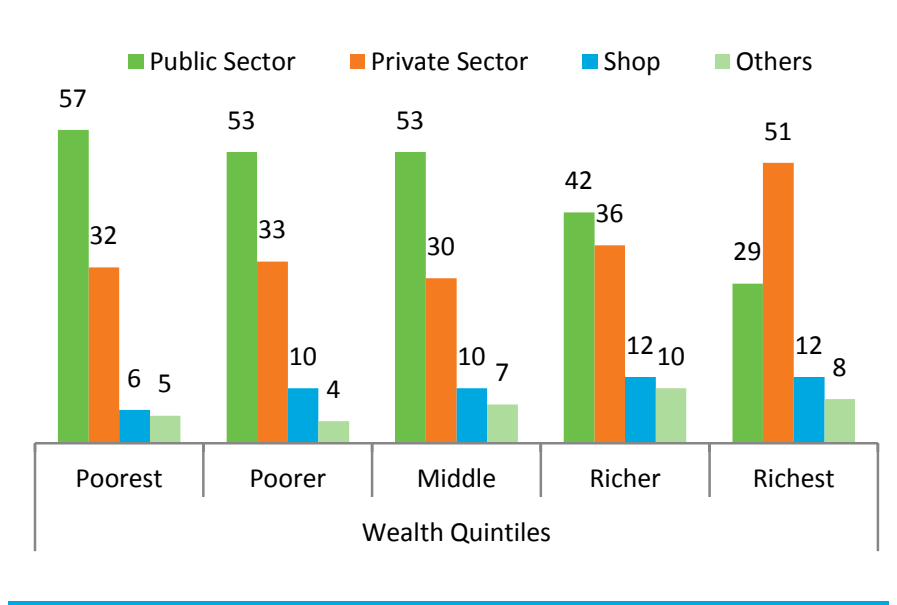

Source: PDHS 2012-13 


\section{Conclusion}

This literature review summarized evidence from research articles, survey findings and project reports to understand the low prevalence of modern contraception in Pakistan. Looking at findings from all these sources together, we find factors related to the supply of methods and the availability and quality of care of family planning services, including counseling on side-effects, to be the principal reasons women are not using modern methods.

That there is high demand for contraception among both Pakistani women and men is exceedingly evident. This can be seen in the proportion of couples wanting to practice spacing between births or limit childbearing. It is also apparent from the fact that more and more married women of reproductive age are trying contraception over time - ever use of contraception has been rising steadily and now stands at around 55 percent. The majority of these women do not practice contraception currently, not because of the desire to have a child, but because of problems related to the method tried. Dissatisfaction with method, method failure and bad experiences with side effects are all strongly related to a lack of knowledge about how a method works, how to manage its side effects, and which methods are more suited to personal preferences and situations. Such causes of discontinuation can be effectively addressed through IEC campaigns on the array of methods available as well as more comprehensive counseling by family planning providers.

In order for that to happen, family planning providers themselves need to be trained and motivated and have a supply of a range of contraceptives to offer clients. The supply of contraceptive methods is inadequate and sporadic. While the private sector has filled some of the gaps in the public provision of FP services, it is not meeting the demands of those in remote rural and poor areas. The public sector needs to increase its provision of these services by tapping into department of health service delivery points. The lack of motivation to provide quality family planning services by providers or by politicians and officials in the health department stems in part from the ambiguity around religious approval of family planning. In order to dispel the misconceptions about family planning in Islam, the FP programs needs learn from other Muslim countries and involve religious leaders and obtain their endorsement. They also need to ensure that family planning information and promotion is targetted at men as well as women. The high prevalence of couple-methods and men's increasing desire to practice contraception indicates that men are not the obstacles to contraceptive uptake. Rather, it highlights how critical it is to include them in programmatic interventions, especially in a patriarchal society like Pakistan.

The program also needs to take advantage of the devolution plan and provide region-specific services. Cultural and material constraints shaping women's contraceptive choices and behaviors vary by province; women in Punjab face extremely different constraints than the women in Balochistan. Even within a province the situation varies greatly; the state of family planning services and contraceptive uptake in urban Sindh, comprising of Karachi and Hyderabad mainly, is completely unlike that of rural Sindh, which lags behind Balochistan in certain indicators. In addition to community-specific programs, future research on understanding obstacles to contraceptive uptake also needs to be cognizant of regional variations.

This review of literature also highlights the gaps in our understanding of the reasons behind low modern contraceptive uptake that future research needs to address. Survey questions on reasons for nonuse elicit responses related to social opposition (primarily in the form of husband disapproval and religious unacceptability) even though supply-side factors seem to have a greater impact on contraceptive uptake. The following three components of Population Council's larger research project aim to unpack this phenomenon further. The second study component conducts in-depth interviews and focus group discussions on FP perceptions, knowledge and preferences not only with women, but with men and FP providers as well. While the third and fourth components focus on establishing a more comprehensive understanding of the current status of access and quality of FP services and the factors that influence the availability of contraceptive supply. 


\section{Extended Bibliography:}

1. Abbasi, S. S., Zafar, M. I., Aslam, M. and Batool, Z. (2008). Effect of female financial empowerment on contraceptive and fertility behavior: Women control on household expenditure. Pakistan Journal of Agricultural Science, 45(3), 112-118.

2. Abdulghani, H. M., Karim, S. I., \& Irfan, F. (2009). Emergency contraception: knowledge and attitudes of family physicians of a teaching hospital, Karachi, Pakistan. Journal of health, population, and nutrition, 27(3), 339.

3. Afsar, H. A., Qureshi, A. F., Younus, M., Gulb, A., \& Mahmood, A. (2003). Factors affecting unsuccessful referral by the lady health workers in Karachi, Pakistan. JPMA-Journal of the Pakistan Medical Association, 53(11), 521-528.

4. Aga Khan University, International Advocacy Seminar on Family Planning and Reproductive Health, February 1213, 2013 (Karachi: Department of Community Health Sciences, Aga Khan University, 2013).

5. Agha, S. (2000). Is low income a constraint to contraceptive use among the Pakistani poor? Journal of Biosocial Science, 32(02), 161-175.

6. Agha, S. (2010). Intentions to use contraceptives in Pakistan: implications for behavior change campaigns. BMC public health, 10(1), 450.

7. Agha, S., \& Beaudoin, C. E. (2012). Assessing a thematic condom advertising campaign on condom use in urban Pakistan. Journal of health communication, 17(5), 601623.

8. Agha, S., \& Davies, J. (1998). Contraceptive social marketing in Pakistan: assessing the impact of the 1991 condom price increases on sales and consumption.

9. Agha, S., \& Meekers, D. (2010). Impact of an advertising campaign on condom use in urban Pakistan. Studies in family planning, 41(4), 277-290.

10. Ahmed T. The state of family planning in Pakistan: Targeting the missing links to achieve development goals. Pathfinder International Pakistan and UNFPA. June 2013.

11. Alam, S., Ahmed, M. H., \& Butt, M. S. (2003). The dynamics of fertility, family planning and female education in Pakistan. Journal of Asian Economics, 14(3), 447-463.

12. Ali, M., \& Ushijima, H. (2005). Perceptions of men on role of religious leaders in reproductive health issues in rural Pakistan. Journal of biosocial science, 37(01), 115-122.

13. Ali, M., Bhatti, M. A., \& Kuroiwa, C. (2008). Challenges in access to and utilization of reproductive health care in Pakistan. Journal of Ayub Medical College Abbottabad, 20(4), 3-7.

14. Ali, M., Bhatti, M. A., \& Ushijima, H. (2004). Reproductive health needs of adolescent males in rural Pakistan: an exploratory study. The Tohoku journal of experimental medicine, 204(1), 17-25.
15. Ali, M., Rizwan, H., \& Ushijima, H. (2004). Men and reproductive health in rural Pakistan: the case for increased male participation. European J. of Contraception and Reproductive Healthcare, 9(4), 260266.

16. Ali, S., \& White, F. M. (2005). Family planning practices among currently married women in Khairpur District, Sindh, Pakistan. Journal of the College of Physicians and Surgeons--Pakistan: JCPSP, 15(7), 422-425.

17. Arif, S., Kamran, I., \& Khan, M. (2007). Exploring the choices of contraception and abortion among married couples in Tret, rural Punjab, Pakistan.

18. Azmat, S. K. (2011). Mobilizing male opinion leaders' support for family planning to improve maternal health: a theory-based qualitative study from Pakistan. Journal of multidisciplinary healthcare, 4, 421.

19. Azmat, S. K., Shaikh, B. T., Hameed, W., Bilgrami, M., Mustafa, G., Ali, M., ... \& Ahmed, A. (2012). Rates of IUCD discontinuation and its associated factors among the clients of a social franchising network in Pakistan. BMC women's health, 12(1), 8.

20. Azmat, S. K., Mustafa, G., Hameed, W., Asghar, J., Ahmed, A., \& Shaikh, B. T. (2013). Social Franchising and Vouchers to Promote Long-Term Methods of Family Planning in Rural Pakistan: A Qualitative Stocktaking with Stakeholders. JPMA. The Journal of the Pakistan Medical Association, 63(4 Suppl 3), S46-53.

21. Basu, A. M. (2005). Ultramodern contraception: Social class and family planning in India. Asian Population Studies, 1(3), 303-323.

22. Bertrand, J. T., Hardee, K., Magnani, R. J., \& Angle, M. A (1995). Access, quality of care and medical barriers in family planning programs. International Family Planning Perspectives, 64-74.

23. Bibi, S., Memon, A., Memon, Z., \& Bibi, M. (2008). Contraceptive knowledge and practices in two districts of Sindh, Pakistan: a hospital based study. JPMA. The Journal of the Pakistan Medical Association, 58(5), 254.

24. Bongaarts, J., \& Bruce, J. (1995). The causes of unmet need for contraception and the social content of services. Studies in family planning, 57-75.

25. Boonstra, H. (2001). Islam, women and family planning A primer. The Guttmacher Report on Public Policy, 4(6), 4-7.

26. Campbell, M., Sahin- Hodoglugil, N. N., \& Potts, M. (2006). Barriers to fertility regulation: a review of the literature. Studies in family planning, 37(2), 87-98.

27. Casterline, J. B., Sathar, Z. A., \& Haque, M. (2001). Obstacles to contraceptive use in Pakistan: A study in Punjab. Studies in family planning, 32(2), 95-110.

28. Cernada, G. P., Rob, A. K., Ameen, S. I., \& Ahmad, M. S. (1993). A situation analysis of family welfare centres in Pakistan. International quarterly of community health education, 14(1), 21-52.

29. Cleland, J., \& Lush, L. (1997). Population and policies in Bangladesh Pakistan. In Forum for Applied Research and Public Policy (Vol. 12, No. 2, pp. 46-50). 
30. Cleland, J., Bernstein, S., Ezeh, A., Faundes, A., Glasier, A., \& Innis, J. (2006). Family planning: the unfinished agenda. The Lancet, 368(9549), 1810-1827.

31. Cleland, J., Lee, K., \& Walt, G. (2000). Politics and fertility: a new approach to population policy analysis. Population Research and Policy Review, 19(1), 1-28.

32. Dharmalingam, A., \& Philip Morgan, S. (1996). Women's work, autonomy, and birth control: Evidence from two south Indian villages. Population Studies,50(2), 187201.

33. Douthwaite, M., \& Ward, P. (2005). Increasing contraceptive use in rural Pakistan: an evaluation of the Lady Health Worker Programme. Health policy and planning, 20(2), 117-123.

34. Douthwaite, M., Miller, P., Sultana, M., \& Haque, M. (1998). Couple communication and sexual satisfaction among withdrawal users in Pakistan. Reproductive Health Matters, 6(12), 41-49.

35. D'Souza, R. M. (2003). Factors influencing the use of contraception in an urban slum in Karachi

Pakistan. Journal of health and population in developing countries, 10.

36. Fikree FF. Reproductive health in Pakistan: evidence and future directions. J Pak Med Assoc 2002; 52(1):34 41.

37. Fikree, F. F., Khan, A., Kadir, M. M., Sajan, F., \& Rahbar, M. H. (2001). What influences contraceptive use among young women in urban squatter settlements of Karachi, Pakistan? International Family Planning Perspectives, 130-136.

38. Fikree, F. F., Saleem, S., \& Sami, N. (2005). A quality of care issue! Appropriate use and efficacy knowledge of five contraceptive methods: Views of men and women living in low socioeconomic settlements of Karachi, Pakistan. JPMA-Journal of the Pakistan Medical Association, 55(9), 363.

39. Rashida, G., Kamran, I., Eshai, K., \& Tasneem, Z. (2013). Post abortion care in Pakistan: The influence of gender and poverty". Population Council. Islamabad.

40. Hafeez, A., Mohamud, B. K., Shiekh, M. R., Shah, S. A. I., \& Jooma, R. (2011). Lady health workers programme in Pakistan: challenges, achievements and the way forward. JPMA-Journal of the Pakistan Medical Association, 61(3), 210.

41. Hakim, Abdul (1993) Contraceptive Use in Pakistan: Variations and Determinants. Pakistan Population Review 4:1. Islamabad: National Institute of Population Studies.

42. Hakim, A., \& Rukanuddin, R. (2000). Are Status of Women and Contraceptive Prevalence Correlated in Pakistan?[with Comments]. The Pakistan Development Review, 1057-1073.

43. Hakim, A., \& Zahir, Z. (2000). Reproductive health indicators in Pakistan: experience of a pilot study.

44. Hakim, A., Hussain, Z., Baqai, M., \& Tanweer, B. U. (2000). Perception of religious leaders about population welfare.
45. Hakim, A., Sultan, M., \& Uddin, F. (2001). Pakistan Reproductive Health and Family Planning Survey. 200001. Preliminary Report. National Institute of Population Studies. Islamabad.

46. Hameed, W., Azmat, S. K., Bilgrami, M., \& Ishaqe, M. (2011). Determining the factors associated with unmet need for family planning: a cross-sectional survey in 49 districts of Pakistan. Pakistan Journal of Public Health, 1(1), 21-27.

47. Hameed, W., Azmat, S. K., Ali, M., Sheikh, M. I., Abbas, G., Temmerman, M., \& Avan, B. I. (2014). Women's Empowerment and Contraceptive Use: The Role of Independent versus Couples' Decision-Making, from a Lower Middle Income Country Perspective. PloS one, 9(8), e104633.

48. Hamid, S., \& Stephenson, R. (2006). Provider and health facility influences on contraceptive adoption in urban Pakistan. International family planning perspectives, 7178.

49. Haq, Z., \& Hafeez, A. (2009). Knowledge and communication needs assessment of community health workers in a developing country: a qualitative study. Human resources for health, 7(1), 59.

50. Haque M., Miller, P. \& Kamran, I. (2012). Role of private sector in delivering birth spacing services in FALAH districts. Population Council, Islamabad.

51. Hardee, K., \& Leahy, E. (2008). Population, fertility and family planning in Pakistan: a program in stagnation. Population Action International, 3(3).

52. Hashmi, S. S., Alam, K., \& Sheraz, A. (1993). Non-users and unmet need for contraception. Islamabad, Pakistan: National Institute of Population Studies.

53. Hennink, M., Diamond, I., Stephenson, R., Clements, S., \& Johnson, F. (2002). Evaluation of Marie Stopes family planning programme in Pakistan. Report of Phase II: Evaluation.

54. Hennink, M., Rana, I., \& Iqbal, R. (2005). Knowledge of personal and sexual development amongst young people in Pakistan. Culture, health \& sexuality, 7(4), 319-332.

55. Hennink, M., Stephenson, R., \& Clements, S. (2001). Demand for Family Planning in Urban Pakistan (No. 2001, p. 3). Opportunities and choices working paper.

56. Hussain, R., Fikree, F. F., \& Berendes, H. W. (2000). The role of son preference in reproductive behaviour in Pakistan. Bulletin of the World Health Organization, 78(3), 379-388.

57. Iqbal Avan, B. I. L. A. L., \& Akhund, S. (2006). Role of family type in the idealization of a larger number of children by husbands in Pakistan. Journal of biosocial science, 38(02), 203-220.

58. Iqbal, H. and John G. (1993) “High fertility in Bangladesh, Nepal, and Pakistan: Motives versus means," in Richard Leete and Iqbal Alam (eds.), The Revolution in Asian Fertility: Dimensions, Causes, and Implications, pp. 175-207. Oxford: Clarendon Press. 
59. Islam, A., Malik, F. A., \& Basaria, S. (2002). Strengthening primary health care and family planning services in Pakistan: some critical issues. JournalPakistan Medical Association, 52(1), 2-6.

60. Jain, A. K., Obare, F., RamaRao, S., \& Askew, I. (2013). Reducing unmet need by supporting women with met need. International perspectives on sexual and reproductive health, 133-141.

61. Jain, A. K., Mahmood, A., Sathar, Z. A., \& Masood, I. (2014). Reducing unmet need and unwanted childbearing: evidence from a panel survey in Pakistan. Studies in family planning, 45(2), 277-299.

62. Jalal, S. (2011). The lady health worker program in Pakistan-a commentary. The European Journal of Public Health, 21(2), 143-144.

63. Jejeebhoy, S. J. (1995). Women's education, autonomy, and reproductive behaviour: Experience from developing countries. OUP Catalogue.

64. Jejeebhoy, S. J., \& Sathar, Z. A. (2001). Women's autonomy in India and Pakistan: the influence of religion and region. Population and development review, 27(4), 687-712.

65. Kamran, I., Khan, M., \& Tasneem, Z. (2013). Involving Men in Reproductive and Fertility Issues: Insights from Punjab. Population Council.

66. Karim, M. S., Zaidi, S., \& Mahmood, N. (1999). Poor Performance of Health and Population Welfare Programmes in Sindh: Case Studies in Governance Failure [with Comments]. The Pakistan development review, 661-688.

67. Kazi, S., \& Sathar, Z. A. (1996). Gender and development: searching for explanations for fertility changes in rural Pakistan

68. Khan, A. (1996). Policy-making in Pakistan's population programme. Health Policy and Planning, 11(1), 30-51.

69. Khan, L. A. (1996). Posing a hidden political threat. Pakistan. No attempt has been made at the national level to evolve a religious consensus on the subject of family planning. Integration, (47), 28-31.

70. Khan, A. (1999). Mobility of women and access to health and family planning services in Pakistan. Reproductive health matters, 7(14), 39-48.

71. Khan, A., and Khan, A. (2012, January) Family Planning in Pakistan: An Overview. Research and Development Solutions, Policy Briefs Series No. 1 ,

72. Khan, A. et. al. (2013, April) Family Planning in Pakistan: Applying What We Have Learned. Research and Development Solutions, Islamabad. , Vol. 63, No. 4 (Suppl. 3).

73. KIANI, M. F. (2003) Motivation and Involvement of Men in Family Planning in Pakistan. The Pakistan Development Review , 42 : 3 , pp. 42 : 3 (Autumn 2003) pp. 197-217.

74. Kiani, M. F. (2000). Understanding men's role in family planning in Pakistan.
75. Larson, A., \& Mitra, S. N. (1992). Family planning in Bangladesh: An unlikely success story. International Family Planning Perspectives, 123-144.

76. Lee, K., Walt, G., \& Cleland, J. (1998). Family planning policies and programmes in eight low-income countries: a comparative policy analysis. Social Science \& Medicine, 47(7), 949-959.

77. Mahmood, A. (2012). Birth spacing and family planning uptake in Pakistan: evidence from FALAH. Population Council, Islamabad.

78. Mahmood, A., Arshad, MJ. \& Sadiq, M. (2012). Situation Analysis of Health Facilities with Special Reference to Family Planning Services in Pakistan. Population Council, Islamabad.

79. Mahmood, A. \& Naz, S. (2012). Contraceptive Use dynamics in Pakistan 2008-09. Population Council, Islamabad.

80. Mahmood, N. (1998). Reproductive goals and family planning attitudes in Pakistan: a couple-level analysis. The Pakistan Development Review, 19-34.

81. Mahmood, N. (2002). Women's Role in Domestic Decision-making in Pakistan: Implications for Reproductive Behaviour. The Pakistan Development Review, 121-148.

82. Mahmood, N. (2005). Assessment of fertility behaviour change in the sociocultural context of Pakistan: implications for the population programme. Asia-Pacific Population Journal, 20(1), 13-36.

83. Mahmood, N., \& Ali, S. M. (1997). Population planning in Pakistan: Issues in implementation and its impact. The Pakistan Development Review, 875-888.

84. Mahmood, N., \& Ringheim, K. (1996). Factors affecting contraceptive use in Pakistan. The Pakistan Development Review, 1-22.

85. Mahmood, N., \& Ringheim, K. (1997). Knowledge, approval and communication about family planning as correlates of desired fertility among spouses in Pakistan. International Family Planning Perspectives, 122-145.

86. Mann, A. A. (2000). Individual Perceptions of Providers and Non-Users of Family Planning in Pakistan: A comparative Analysis. Int. J. Agri. Biol, 2, 310-314.

87. Mason, K. O. (1997). Explaining fertility transitions. Demography, 34(4), 443-454.

88. Mason, K. O., \& Smith, H. L. (2000). Husbands' versus wives' fertility goals and use of contraception: The influence of gender context in five Asian countries. Demography, 37(3), 299-311.

89. Mir A.M and Rashida G. Islam and family planning: changing perceptions of healthcare providers and medical faculty in Pakistan. Glob Health Science Practice 2013;1(2):228-236

90. Mishra, A., Nanda, P., Speizer, I. S., Calhoun, L. M., Zimmerman, A., \& Bhardwaj, R. (2014). Men's attitudes on gender equality and their contraceptive use in Uttar Pradesh India. Reproductive Health, 11(1), 41. 
91. Mumtaz, Z., \& Salway, S. (2005). 'I never go anywhere': extricating the links between women's mobility and uptake of reproductive health services in Pakistan. Social science \& medicine, 60(8), 1751-1765.

92. Mumtaz, Z., \& Salway, S. (2009). Understanding gendered influences on women's reproductive health in Pakistan: moving beyond the autonomy paradigm. Social Science \& Medicine, 68(7), 1349-1356.

93. Mumtaz, Z., Salway, S., Waseem, M., \& Umer, N. (2003). Gender-based barriers to primary health care provision in Pakistan: the experience of female providers. Health policy and planning, 18(3), 261-269.

94. Mustafa, R., Afreen, U., \& Hashmi, H. A. (2008). Contraceptive knowledge, attitude and practice among rural women. J Coll Physicians Surg Pak, 18(9), 542545.

95. Nasir, J. A., \& Hinde, A. (2011). Factors associated with contraceptive approval among religious leaders in Pakistan. Journal of biosocial science, 43(05), 587-596.

96. Naz, S., Tayyab, S., Ali, L., \& Yasir, R. (2009). Emergency contraception: knowledge and attitude among females. Journal of Surgery Pakistan (international), 14(2).

97. National Institute of Population Studies (NIPS) and IRD/Macro International Inc. (1992). Pakistan Demographic and Health Survey 1990-91. Columbia, Maryland USA: NIPS and IRD/Macro International Inc.

98. National Institute of Population Studies (NIPS) and Macro International Inc. (2008). Pakistan Demographic and Health Survey 2006-07. Islamabad, Pakistan: National Institute of Population Studies and Macro International Inc.

99. National Institute of Population Studies (2013). Pakistan Demographic and health Survey 201213. Islamabad. Islamabad and Calverton, Maryland, USA: NIPS and ICF International.

100. Nishtar, S., Bhutta, Z. A., Jafar, T. H., Ghaffar, A., Akhtar, T., Bengali, K., \& Rahim, E. (2013). Health reform in Pakistan: a call to action. The Lancet, 381(9885), 22912297.

101. Omer, K., Mhatre, S., Ansari, N., Laucirica, J., \& Andersson, N. (2008). Evidence-based training of frontline health workers for door-to-door health promotion: a pilot randomized controlled cluster trial with Lady Health Workers in Sindh Province, Pakistan. Patient education and counseling, 72(2), 178185.

102. Piet-Pelon, N. J., Rob, U., \& Khan, M. E. (1999). Men in Bangladesh India and Pakistan: reproductive health issues.

103. Population Council. (1997) The Gap Between Reproductive Intentions and Behaviour: A Study of Punjabi Men and Women. Population Council, Islamabad.

104. Population Council (2010). Examining Fertility Change and Its Impact on Household Poverty and Welfare. World Bank Series. Islamabad.
105. Population Council (2014) "Prioritizing Family Planning for Achieving provincial Maternal Child Health and Development Goals"

106. Qureshi, R., \& Adamchak, D. J. (1996). Determinants of marital fertility in Pakistan: the impact of education, work and family planning. Sociological focus, 29(2), 167-178.

107. Rahman, A. (1994). View towards Women's Reproductive Rights Perspective on Selected Laws and Policies in Pakistan, A. Whittier L. Rev., 15, 981.

108. Ravindran, T. K. (2010). Privatisation in reproductive health services in Pakistan: three case studies. Reproductive health matters, 18(36), 13-24.

109. Raza H, Sheraz A, Zafar R, Khan N, Ali H. Effect of Islamic perception on family planning practices. OIDA Int J Sust Dev. 2012;5(3):85-96.

110. Rehan, N., Inayatullah, A., \& Chaudhary, I. (1999). Norplant: users' perspective in Pakistan. Advances in contraception, 15(2), 95-107.

111. Rukanuddin, A. R., \& Hardee-Cleaveland, K. (1992). Can family planning succeed in Pakistan? International Family Planning Perspectives, 109-121.

112. Saleem, A., \& Pasha, G. R. (2008). Women's reproductive autonomy and barriers to contraceptive use in Pakistan. European J. of Contraception and Reproductive Healthcare, 13(1), 83-89.

113. Saleem, S., \& Bobak, M. (2005). Women's autonomy, education and contraception use in Pakistan: a national study. Reproductive health, 2(8), 1-8.

114. Santhya, K. G. (2003). Changing family planning scenario in India: an overview of recent evidence.

115. Sathar, Z. A., \& Mason, K. O. (1993). How female education affects reproductive behavior in urban Pakistan. In Asian and Pacific Population Forum (Vol. 6, No. 4, pp. 93-103).

116. Sathar, Z. A., Singh, S., \& Fikree, F. F. (2007). Estimating the incidence of abortion in Pakistan. Studies in Family Planning, 38(1), 11-22.

117. Sathar, Z., Singh, S., Rashida, G., Shah, Z., \& Niazi, R. (2014). Induced Abortions and Unintended Pregnancies in Pakistan. Studies in family planning,45(4), 471-491.

118. Sathar, Z. A., Singh, S., Shah, Z. H., Rashida, G., Kamran, I., \& Eshai, K. (2013). Post-Abortion Care in Pakistan: A National Study. Population Council. Islamabad, Pakistan.

119. Sathar, Z. A., \& Kazi, S. (1997). Women's autonomy, livelihood and fertility: a study of rural Punjab. Women's autonomy, livelihood and fertility: a study of rural Punjab.

120. Sathar $Z$ and Zaidi B. Status of Family Planning in Pakistan. UNFPA - ICOMP REGIONAL CONSULTATION Family Planning in Asia and the Pacific Addressing the Challenges: 8-10 December 2010; Bangkok, Thailand.

121. Sathar, Z, Laura Reichenbach, and Arshad Mahmood (2008) what's hindering fertility decline in Pakistan: perceptions and realities. Presented at Population Association of America Meeting 2008 held in New Orleans, LA, April 17-19. 
122. Schuler, S. R., Hashemi, S. M., Cullum, A., \& Hassan, M. (1996). The advent of family planning as a social norm in Bangladesh: women's experiences. Reproductive Health Matters, 4(7), 66-78.

123. Seiber, E. E., Bertrand, J. T., \& Sullivan, T. M. (2007). Changes in contraceptive method mix in developing countries. International Family Planning Perspectives, 117-123.

124. Shafique, A., and I, Kamran. (2006) Exploring further the choices of contraception and abortion among married couples in Pakistan: An in depth view of Tret, Punjab. Population Council, Islamabad.

125. Shah, I. H., \& Cleland, J. G. (1993). High fertility in Bangladesh Nepal and Pakistan: motives vs. means.

126. Shah, N. A., Nisar, N., \& Qadri, M. H. (2008). Awareness and pattern of utilizing family planning services among women attending Urban Health Care Center Azizabad Sukkur. Pak Journal Medical Science, 24(4), 550-5.

127. Shah, N. M., Wang, W., \& Bishai, D. M. (2011). Comparing private sector family planning services to government and NGO services in Ethiopia and Pakistan: how do social franchises compare across quality, equity and cost? Health policy and planning, 26 (suppl 1), i63i71.

128. Shaikh, B. T. (2010). Unmet need for family planning in Pakistan-PDHS 2006-2007: it's time to re-examine déjà vu. Open Access Journal of Contraception, 1, 113118.

129. Shaikh, B. T., \& Hatcher, J. (2005). Health seeking behaviour and health service utilization in Pakistan: challenging the policy makers. Journal of Public Health, 27(1), 49-54.

130. Shelton, J. D., Bradshaw, L., Hussein, B., Zubair, Z., Drexler, T., \& McKenna, M. R. (1999). Putting unmet need to the test: community-based distribution of family planning in Pakistan. International Family Planning Perspectives, 191-195.

131. Soomro, G. Y., \& Mahmood, N. (2004). Female education and fertility: Implications for family planning programme. In 20th AGM and Conference of the Pakistan Society of Development Economists. Islamabad: Pakistan Institute of Development Economics.
132. Stephenson, R., \& Hennink, M. (2004). Barriers to family planning use amongst the urban poor in Pakistan.

133. Sultan, M., Cleland, J. G., \& Ali, M. M. (2002). Assessment of a new approach to family planning services in rural Pakistan. American Journal of Public Health, 92(7), 1168-1172.

134. United Nations Population Division, 2002. Abortion Policies: A Global Review, New York: United Nations.

135. USAID I DELIVER PROJECT (2013). Pakistan: Stock Analysis at Service Delivery Points for USAID-Supported Contraceptives Final Report. Arlington, Va.: USAID | DELIVER PROJECT, Task Order 4.

136. (Wazir et. al, 2013): National program for family planning and primary health care Pakistan: a SWOT analysis. Reproductive Health.

137. Westoff, C. F., \& Bankole, A. (1999). Mass media and reproductive behavior in Pakistan India and Bangladesh.

138. Winkvist, A., \& Akhtar, H. Z. (2000). God should give daughters to rich families only: attitudes towards childbearing among low-income women in Punjab, Pakistan. Social Science \& Medicine, 51(1), 73-81.

139. Zafar, M. I., Asif, F., \& Adil, S. (2003). Religiosity as a Factor of Fertility and Contraceptive Behavior in Pakistan. Journal of Applied Sciences, 3, 158-166.

140. Zaidi, B. and Naz, S. (2011). Contraceptive Use in Pakistan; couple preferences, perceptions and practices. Presented at International FP Conference, Senegal. 